\title{
Study on Tensile Properties of Nylon 66 Reinforced Composites
}

\author{
Ho Ming Hsiung * \\ Department of Mechanical Engineering \\ Taoyuan Innovation Institute of Technology \\ Taoyuan, Taiwan, R.O.C. \\ e-mail: morrisho@tiit.edu.tw \\ * Corresponding Author \\ Wang Pin Ning \\ Department of Material and Fiber \\ Taoyuan Innovation Institute of Technology \\ Taoyuan, Taiwan, R.O.C.
}

\author{
Hwang Jiun Ren
Department of Mechanical Engineering
National Central University
Taoyuan, Taiwan, R.O.C. \\ Hwang Jiun Ren
Department of Mechanical Engineering
National Central University
Taoyuan, Taiwan, R.O.C. \\ Hwang Jiun Ren
Department of Mechanical Engineering
National Central University
Taoyuan, Taiwan, R.O.C. \\ Hwang Jiun Ren
Department of Mechanical Engineering
National Central University
Taoyuan, Taiwan, R.O.C.
}

Kuo Shun Chi

Department of Mechanical Engineering

Taoyuan Innovation Institute of Technology

Taoyuan, Taiwan, R.O.C.

\begin{abstract}
Nylon 66 is widely used in the vehicle interior, electronic parts and accessories. Nylon 66 as polymer material is added reinforce glass fiber to increase material properties. In parts forming process, injection mold method is widely used in polymer forming industry. In the study, the effects of injection molding process on the pseudo-static and high strain rate tensile properties of Nylon 66 composites are discussed. From the results, the tensile strength and Young's modulus increase with increasing the amount of glass fibers, but the elongation decreases with opposite trend. In high strain rate, the ultimate tensile stress, elongation of Nylon 66 composites increases with increasing strain rate apparently, while elongation is almost invariant for unreinforced Nylon 66. About fracture surface observation, the fibers in melt flow direction are broke and pulled out at quasi-static tensile test. And the fiber is breakage and the fibers are pull out from base material in melt flow direction are at high strain rate test. In this study, the results could provide nylon 66 composite properties for design application.
\end{abstract}

Keywords-tensile; Nylon 66; short glass fiber; injection molding; high strain rate

\section{INTRODUCTION}

Plastic materials with attractive features at light weight, low cost, colorful surface, short production cycle, and corrosion resistance, are often used in industrial applications. The injection molding method has excellent surface accuracy, short processing cycle, low cost, and can be used to molding complex shapes. Among plastics material, nylon 66, wear resistance, self-lubricating, corrosion resistance and good formability.

Li [1] studied the factors of acid concentration, temperature and time affect at the mechanical behavior of the fibers of Nylon 56, Nylon 6 and Nylon 66. They found that the strength of all three nylon fibers have obvious decrease if treated in acetic acid concentration. Mehat [2] investigated the recycling of plastic products to find a method to manage the increasing amount of Nylon 66 with glass fiber waste generated by the gear industry. In the study, the gears' Young's modulus and elongation at break are also identified and examined with injection parameters. $\mathrm{Hu}$ [3] studied and compared three types finite element models, short carbon fiber reinforced nylon spur gear pairs, and steel and unreinforced nylon spur gear pairs. The research results showed that the higher strength and better performance nylon gear can fabricate by properly controlled injection molding processes. Basavaraj [4] investigated the influence of silane-coated short glass fibers (SGF) on the mechanical and wear characteristics of nylon 66 composites. It was found that the addition of glass fibers as well as MoS2 has significantly improved the tensile strength, tensile modulus, and impact strength of the nylon 66. Ho [5-6] had studied PC/ABS blend in low cycle fatigue and fracture toughness properties under injection mold conditions: filling time, melting temperature, mold temperature. These studies were to find out the optimum mold conditions for PC/ABS dynamic application.

This study employed three types weight percent short glass fiber reinforced Nylon 66 with single parameter experimental design method. In order to define the injection molding process parameters, the mold flow analysis software (C-MOLD) is used for simulation and analysis, In the mechanical properties study, four control parameters: melting temperature, mold temperature, filling time and packing pressure was used to explore the influence of injection molding conditions. After the experiment, the specimen fracture surfaces were examined with the scanning electron microscope, in order to understand the related fracture mechanism.

\section{METHOD}

\section{A. Materials}

The engineering plastic Nylon 66 and short glass fiberreinforced composite materials used in this study are produced from the DuPont. Three types Nylon with short glass fibers as a percentage of 0 wt.\%, 13 wt.\% and 33 wt.\%, respectively. The material brand name [7] is: DuPont Zytel 101L (excluding fiber), DuPont Zytel 70G13L (including glass fiber 13 wt.\%.) and DuPont Zytel 70G33L (including glass fiber 33 wt.\%.), The average density was $1.14 \mathrm{~g} / \mathrm{cm} 3,1.22 \mathrm{~g} / \mathrm{cm} 3$ and $1.38 \mathrm{~g} / \mathrm{cm} 3$. 


\section{B. Specimen preparation}

The injection mold layout is shown in Fig .1. The test specimens used in experiments are melting glue injection from the tail end. One specimen's melt flow direction is parallel to the tensile test loading direction (P-direction), another specimen melt flow direction is perpendicular to the tensile loading direction (AP-direction).

The molding conditions were filling time set to 0.5/1.5/2.5/3.5 seconds, melt temperature designed for $265 / 275 / 290 / 305{ }^{\circ} \mathrm{C}$ and mold temperature was set to $60 / 75 / 90 / 105{ }^{\circ} \mathrm{C}$ and packing pressure was set to 18/26/34/42 MPa. The specimen number and the detailed conditions of the molding are listed in Tab . I.

During the injection molding, the material was preheated at $79{ }^{\circ} \mathrm{C}$ for 12 hours to get rid of the moisture before it can be used in an injection molding machine. The specimens were cooled to room temperature in atmosphere, after the specimens being ejected out of the mold.

\section{Tensile Test}

Tensile test is based on ASTM D638-00 standard [8] at room temperature, tensile test stroke control, the tensile rate of $1 \mathrm{~mm} / \mathrm{min}$.

High strain rate tensile testing method using Hopkinson Pressure method [9] three strain rates are $20 \mathrm{~s}-1,60 \mathrm{~s}-1$ and $100 \mathrm{~s}-1$ for high strain rate tensile test.

After the test, specimen fracture surface was observed by a scanning electron microscope (SEM).

\section{RESULTS AND DISCUSSIONS}

\section{A. Quasi-static tensile test}

In quasi-static tensile test specimens, the melt flow direction was divided into two injection flow $\mathrm{P}$ and AP direction.

\section{1) P-direction}

As shown in Fig .2. the specimen of $\mathrm{P}$ direction for the ultimate tensile strength of the fiber content was influenced by different injection molding conditions. It could be observed from the Fig .2 (a), the tensile strength of Nylon 66 would decrease when the melting temperature increase, and its optimum melting temperature was $265{ }^{\circ} \mathrm{C}$. The cooling rate of the molded specimens was reduced because of the higher melt temperature. It accelerated molecular relaxation rate and extends the molecular relaxation time. It also was reducing the surface molecules orientation and forward retention molecular layer thickness at the surface. These results had same phenomenon as Cox [10] showed.

In Fig .2 (b) showed that the mold temperature conditions had little impact on the ultimate strength. As the result showed, the better mold temperature was $105^{\circ} \mathrm{C}$.

About filling time conditions, Fig .2(c) showed the filling time of 2.5 seconds was the better injection condition for ultimate strength. This is due to longer filling time could cause thick solid layer so that the tensile strength of a rising trend.

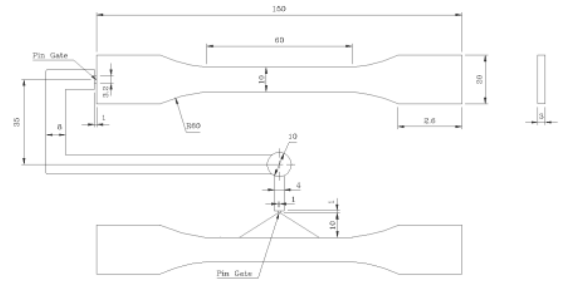

Figure 1. The specimens layout in injection mold.

TABLE I. SPECIMENS Forming CONDITIONS

\begin{tabular}{|c|c|c|c|c|}
\hline $\begin{array}{c}\text { Specimen } \\
\text { Identification }\end{array}$ & $\begin{array}{c}\text { Melting } \\
\text { Temperature } \\
\left({ }^{\circ} \boldsymbol{C}\right)\end{array}$ & $\begin{array}{c}\text { Mold } \\
\text { Temperature } \\
\left({ }^{\circ} \text { C }\right)\end{array}$ & $\begin{array}{c}\text { Filling } \\
\text { Time }(\mathbf{s})\end{array}$ & $\begin{array}{c}\text { Packing } \\
\text { Pressure } \\
(\text { MPa })\end{array}$ \\
\hline M265 & 265 & 75 & 2.5 & 42 \\
\hline M275 & 275 & 75 & 2.5 & 42 \\
\hline M290 & 290 & 75 & 2.5 & 42 \\
\hline M305 & 305 & 75 & 2.5 & 42 \\
\hline C60 & 290 & 60 & 2.5 & 42 \\
\hline C75 & 290 & 75 & 2.5 & 42 \\
\hline C90 & 290 & 90 & 2.5 & 42 \\
\hline C105 & 290 & 105 & 2.5 & 42 \\
\hline T0.5 & 290 & 75 & 0.5 & 42 \\
\hline T1.5 & 290 & 75 & 1.5 & 42 \\
\hline T2.5 & 290 & 75 & 2.5 & 42 \\
\hline T3.5 & 290 & 75 & 3.5 & 42 \\
\hline P18 & 290 & 75 & 2.5 & 18 \\
\hline P26 & 290 & 75 & 2.5 & 26 \\
\hline P34 & 290 & 75 & 2.5 & 34 \\
\hline P42 & 290 & 75 & 2.5 & 42 \\
\hline
\end{tabular}

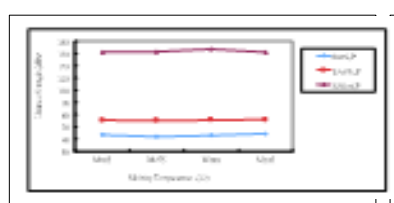

(a) Melting temperature

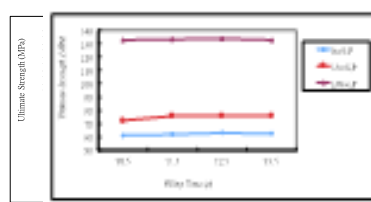

(c) Filling time

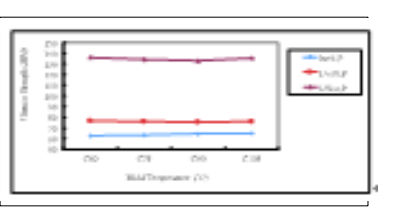

(b) Mold temperature

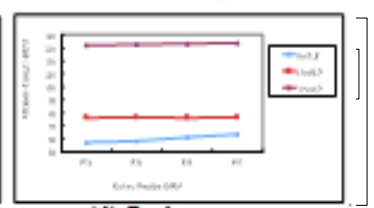

(d) Packing pressure
Figure 2. Quasi-static tensile test in P-direction.

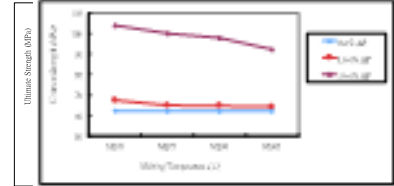

(a) Melting temperature

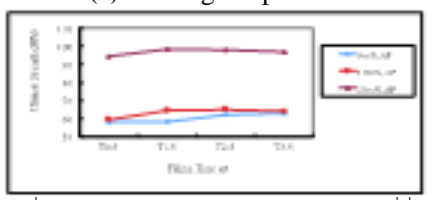

(c) Filling time

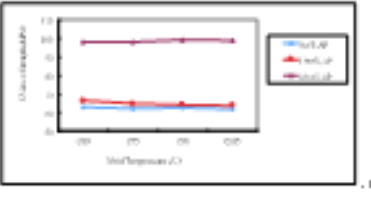

(b) Mold temperature
Figure 3. Quasi-static tensile test in AP-direction. 
In Fig .2 (d), the packing pressure increases helped the tensile strength to increase. This was due to non-fibrous Nylon 66 at higher packing pressure; the molecules density of the material was large, so that the ideal holding pressure was $42 \mathrm{MPa}$.

And in different fiber content of Nylon 66 at melting temperature and mold temperature conditions had the same trend with increasing temperature and decreasing the tensile strength. The ideal melting temperature was $290^{\circ} \mathrm{C}$ and the mold temperature was $60{ }^{\circ} \mathrm{C}$. The lower mold temperature caused the specimen with faster cooling rates. In injection process, the fibers in Nylon 66 with same direction would form a thick and soft skin, and cause the tensile strength decrease.

\section{2) AP-direction}

Fig .3 was showed, the tensile test results of specimens in AP direction according to the fiber contents and injection molding conditions.

It could also be seen from Fig .3, the tensile strength variation of the unreinforced Nylon 66 and Nylon 66 with glass fiber had the same trend as P-direction test results at melting temperature, mold temperature and filling time conditions.

However, packing pressure condition had the opposite trend. Mainly because the AP-direction specimen's packing process was start from the center area, so that the intermolecular could achieve higher density at lower packing pressure. But in Fig. 3(d), the packing pressure continued to increase, it made ultimate strength decrease. The reason was that the specimens' large molecules density undermined the bonding force between molecules.

\section{3) Young's modulus}

Fig .4. was showed the Young's modulus of Nylon 66 with the fiber content and injection mold direction of the specimens.

Young's modulus increased as the glass fiber content increases. The Nylon 66 with 33 wt.\% glass fiber had the highest Young's modulus.

Comparison of Fig. 2 to 4 can obviously find that tensile strength and Young's modulus are increasing with the increase of fiber contain.

\section{4) Elongation}

Fig .5 is showed the specimens' elongation under fiber content and injection mold direction of Nylon 66 specimen.

It could be found that the fiber content increased with elongation decreased rapidly.

The elongation of P-direction unreinforced Nylon 66 and Nylon 66 with glass fiber was higher than APdirection. Nylon 66 in P-direction without glass fiber had the highest elongation; its elongation was over $300 \%$. In the while, the elongation of Nylon 66 with glass fiber only had 1 to $10 \%$.

In addition, in Fig .5, it was found that Nylon 66 with 13 wt.\% glass fiber had a minimum elongation. This is because the unreinforced Nylon 66 as base materials has the high ductility and toughness properties. While adding a small amount of fibers, it would destroy the bonding force between the molecules, so that a substantial decreased in ductility.

After Nylon 66 fiber contain increased up to $33 \mathrm{wt} \%$, the force undertake mechanism was changed. The fiber in Nylon 66 was the majority factor to bear tensile strength, so that the elongation was slight raised.

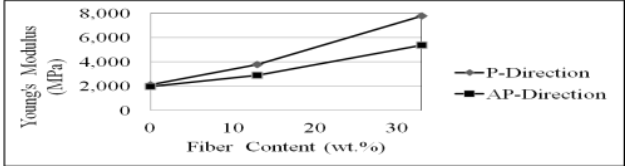

Figure 4. The Young's modulus at quasi-static tensile test.

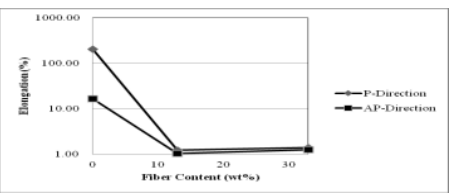

Figure 5. The elongation at quasi-static tensile test.

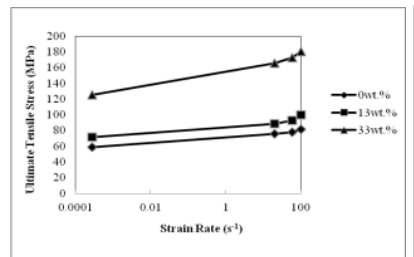

(a) P-direction

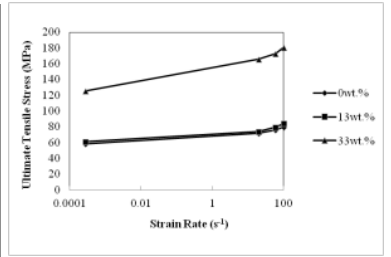

(b) AP-direction
Figure 6. The ultimate tensile stress at high strain rate.

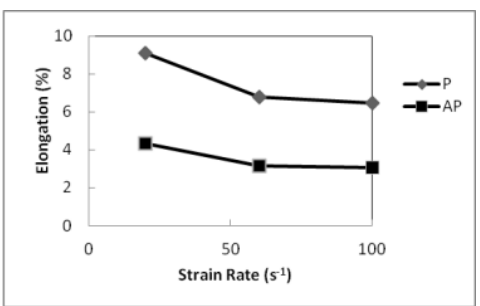

(a) Nylon 66

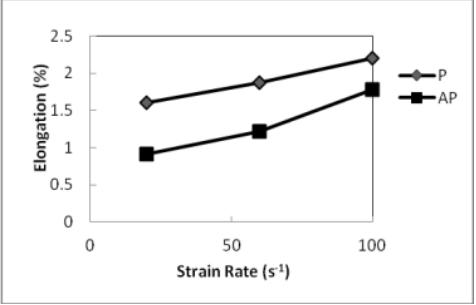

(b) Nylon 66 with 13 wt.\% glass fiber

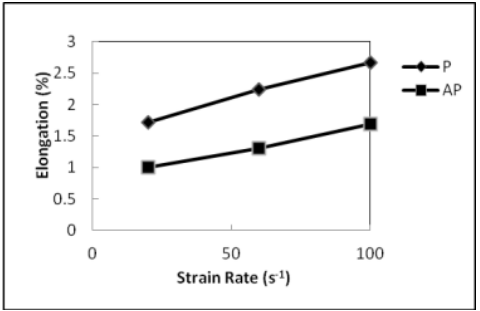

(c) Nylon 66 with 33 wt.\% glass fiber

Figure 7. The elongation at high strain rate.

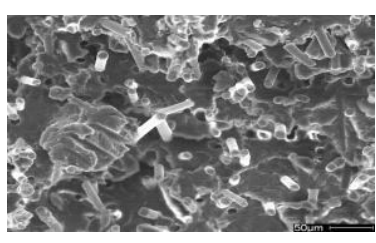

(a) P-direction

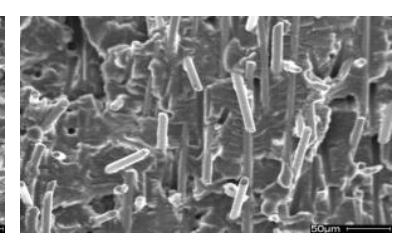

(b) AP-direction
Figure 8. The fracture surface of Nylon 66 with 33 wt. $\%$ glass fiber at melting temperature $290^{\circ} \mathrm{C}$ in quasi-static tensile test. 


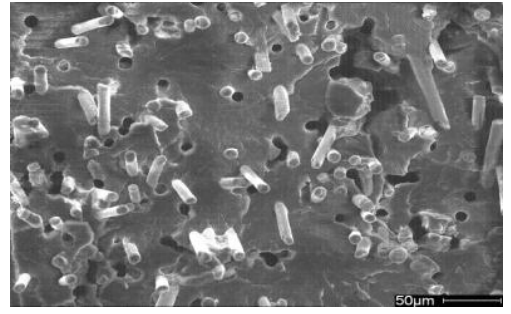

Figure 9. The fracture surface of Nylon 66 with 33 wt.\% glass fiber at melting temperature $265^{\circ} \mathrm{C}$ in $60 \mathrm{~s}^{-1}$ high strain tensile test.

\section{B. High strain rate tensile test}

It was showed the tensile strength of Nylon 66 in Fig. 6(a) P-direction and Fig. 6(b) AP-direction under high tensile strain conditions. It could be found in Fig .6. increasing strain rate would make ultimate tensile stress rise. When the strain rate was $100 \mathrm{~s}-1$, the three materials had highest tensile strength.

Fig .7 was showed the elongation of Nylon 66 for fiber content and injection mold direction.

In Fig. 7(a), the unreinforced Nylon 66 had higher strength at the strain rate of $20 \mathrm{~s}-1$. When the strain rate increased to $60 \mathrm{~s}-1 \sim 100 \mathrm{~s}-1$, there were small changes in elongation and slight decline phenomenon. From the trends could still be found that the elongations in $\mathrm{P}$ direction are greater than the AP-direction.

However, the fiber reinforced Nylon 66 with increasing fiber content, there is a rising phenomenon as showed in Fig .7(b) and Fig .7(c).

\section{Fractograph}

\section{1) Quasi-static tensile test}

Fig .8(a) in P-direction and (b) in AP-direction was the fracture surfaces observation of Nylon 66 with $33 \%$ glass fiber at melting temperature $290^{\circ} \mathrm{C}$.

Photos could be clearly observed, when injection mold in P-direction, the fibers were arranged horizontally in the specimen tensile loading direction. As shown in Fig .8(a), the fracture mechanisms are glass fiber broke and fiber pull out.

And in Fig .8(b), when the injection mold direction in AP-direction, the fibers distribution was mostly perpendicular to the direction of tensile loading direction. The fracture mode of the glass fiber was shear cut and fiber splicing detached.

\section{2) High strain rate tensile test}

Fig .9 is showed the fracture surface microstructure of Nylon 66 with 33 wt.\% glass fiber at melting temperature $265^{\circ} \mathrm{C}$, P-direction, and $60 \mathrm{~s}-1$ strain rate.

The figure was showed the material at high strain rates, the damage mechanisms mainly are the fiber breakage and the fibers are pull out from base material.

The phenomenon of the base surface had been opened. This phenomenon is never seen in the quasi-static tensile test. Therefore, Nylon 66 with glass fiber and base material had higher plastic deformation and a phenomenon of the increase ductility under higher strain rates conditions.

\section{CONCLUSIONS}

Based on the results, the following conclusions can be obtained:
1. The tensile strength, Young's modulus and elongation of Nylon 66 and glass fiber reinforced Nylon 66 in P-direction is greater than AP-direction. The tensile strength and Young's modulus are increased with the increasing amount of fiber containing.

2. The best experimental parameters of Nylon 66 on the P-direction is mold temperature of $265{ }^{\circ} \mathrm{C}$, mold temperature of $105{ }^{\circ} \mathrm{C}$, filling time $2.5 \mathrm{~s}$, holding pressure $42 \mathrm{MPa}$. The optimum parameters for Nylon 66 with glass fiber are melting temperature $290{ }^{\circ} \mathrm{C}$, mold temperature $60{ }^{\circ} \mathrm{C}$, filling time $2.5 \mathrm{~s}$, and packing pressure $42 \mathrm{MPa}$.

3. In high strain rate experimental conditions, increases with the amount of fiber contain, it helps tensile strength and Young's modulus to increase.

4. The elongations of P-direction are greater than APdirection in quasi-static tensile test and high strain rate tensile test. In addition, the elongation of fiber reinforced Nylon 66 showed that a positive relation between fiber contains and strain rate.

5. The unreinforced Nylon 66 has better elongation value at strain rate $20 \mathrm{~s}-1$, but when the strain rate is increased to $60 \mathrm{~s}-1 \sim 100 \mathrm{~s}-1$, the elongation remains constant with a slight decline phenomenon.

\section{ACKNOWLEDGMENT}

In this paper, the research was sponsored by the National Science Council (Project No. NSC 92-2212-E008-021 and MOST 104-2221-E-253-004)

\section{REFERENCES}

[1] Y. L. Li, X. M. Hao, Y. F. Guo, X. Chen, Y. Yang, J. M. Wang, "Study on the Acid Resistant Properties of Bio-Based Nylon 56 Fiber Compared with the Fiber of Nylon 6 and Nylon 66,", Advanced Materials Research, vol. 1048, Oct. 2014, pp. 57-61.

[2] N. M. Mehat, N. S. Zakarria, S. Kamaruddin, "Investigating the Effects of Blending Ratio and Injection Parameters on the Tensile Properties of Glass Fiber-Filled Nylon 66 Composite Gear," Applied Mechanics and Materials, vol. 548-549, Apr. 2014, pp. 4347.

[3] Zhong Hu, "Strength Evaluation and Failure Prediction of Short Carbon Fiber Reinforced Nylon Spur Gears by Finite Element Modeling," Applied Composite Materials, vol. 20, Jun. 2013, pp 315-330.

[4] Basavaraj, E., Ramaraj, B. and Siddaramaiah, "A study on mechanical, thermal, and wear characteristics of nylon 66/molybdenum disulfide composites reinforced with glass fibers," Polymer Composite, vol. 33, 2012, pp. 1570-1577.

[5] Ho M. H., Wang P. N. and Kuo S. C., "Research on the Low Cycle Fatigue Properties of PC/ABS Blend," Advanced Materials Research, vol. 1095, 2015, pp. 938-941.

[6] Ho M. H., Wang P. N., Yeh J. P. and Li S. J., "Research on Fatigue Fracture Characterization of $\mathrm{PC} / \mathrm{ABS}$ Blend," 5th International Conference on Advanced Design and Manufacturing Engineering (ICADME 2015), Sep. 2015, pp. 1899-1902, doi:10.2991/icadme15.2015.351.

[7] The Engineering Web, DuPont Zytel, http://www.ibuyplastic.com/.

[8] "Standard Test Method for Tensile Properties of Plastics," Annual Book of ASTM Standards, D638-00, 2000, pp. 44-56.

[9] Sierakowski, R. L., "Strain Rate Behavior of Composites: issues, "The American Society of Mechanical Engineers, vol. 48, 1995, pp. 1-6.

[10] Cox, H. W., and Mentzer, C. C., "Injection Molding: The Effect of Fill Time on Properties," Polymer Engineering and Science, vol. 26, 1986, pp. 488-498. 